\title{
Death due to Covid-19 in a Patient with Diabetes, Epilepsy, and Gout comorbidities
}

\author{
Amir Reza Safdarian ${ }^{1}$, Kaveh Momenzadeh ${ }^{2}$, Farima Kahe $^{2}$, Pooya Farhangnia ${ }^{3}$, and nima \\ rezaei $^{4}$ \\ ${ }^{1}$ Alborz University of Medical Sciences \\ ${ }^{2}$ Beth Israel Deaconess Medical Center \\ ${ }^{3}$ Iran University of Medical Sciences \\ ${ }^{4}$ Tehran University of Medical Sciences
}

September 21, 2020

\begin{abstract}
There is evidence of increased incidence, rapid progression, and poor prognosis of Covid-19 in patients with underlying comorbidities such as diabetes and epilepsy. It is crucial to develop effective treatment regimens for these patients. Multiple organ failure is the most common cause of death in Covid-19 patients.
\end{abstract}

Key words: Covid-19, Coronavirus, Diabetes, Epilepsy, Comorbidities

\section{Key Clinical Message}

Developing effective treatment regimens for Covid-19 patients with multiple comorbidities - especially diabetes and epilepsy - is crucial, as patients' past medical history is an essential contributor to possible organ injuries in Covid-19 patients.

1. Introduction

In December 2019, an outbreak of unknown acute respiratory tract infection originated in Wuhan, China 1. Shortly after first lower respiratory tract infection cases, the World Health Organization (WHO) named this newly emerged coronavirus as Severe acute respiratory syndrome coronavirus 2 (SARS-CoV-2) and its resultant disease as coronavirus disease 2019 (Covid-19) ${ }^{2,3}$. Coronaviruses are a large class of viruses that often cause mild to moderate upper respiratory tract infection. However, three of them have arisen from animal sources in the past two decades, resulted in Severe acute respiratory syndrome (SARS) and Middle East Respiratory Syndrome (MERS) epidemics as well as the novel Covid-19 pandemic ${ }^{4-6}$.

There is evidence of increased incidence, rapid progression, and poor prognosis of Covid-19 in patients with underlying comorbidities ${ }^{7-9}$. Diabetes is a significant risk factor for hospitalization and adverse outcome in these patients ${ }^{10-12}$, as similar evidence was reported for two previous CoV infections, SARS and MERS 4, 5, 13. Moreover, several studies have suggested epilepsy as a potential risk factor to morbidity and mortality in Covid-19 patients; nevertheless, the association as of yet is unclear ${ }^{14-16}$.

Herein, we report a confirmed case of Covid-19 patient with a history of multiple underlying diseases, including diabetes, epilepsy, and gout. The patient died a week after intensive care unit (ICU) admission. We desire to highlight recesses in the knowledge that require further studies related to Covid-19 in patients with underlying comorbidities.

2. Case presentation 
On February 18, 2020, a 47-year-old with acute respiratory syndrome, high fever (39.6 C) and severe shortness of breath was admitted to ICU at Ghaem Hopital in Karaj, Iran. Regarding strong suspicion of the Covid-19 infection complete laboratory tests and Spiral chest computed tomography (CT) scan without contrast were performed for the patient. CT scan findings were consisted of bilateral ground glass opacities predominantly in lower zones, multiple atelectasis bilaterally in same regions, and elevation of right hemidiaphragm. No evidence of pericardial effusion, pleural fluid collection/thickening were reported. Imaging findings were characteristic of pneumonia attributed to SARS-CoV-2.

The patient had a history of epilepsy, gout (uric acid $9.0 \mathrm{mg} / \mathrm{dl}$ ) and diabetes. Initial laboratory findings were described as follows: low white blood cells (WBC, 3400 / microliter), high blood sugar (BS, $179 \mathrm{mg} / \mathrm{dl}$ ), impaired liver function tests; (SGOT/AST, $65 \mathrm{U} / \mathrm{L}$ and SGPT/ALT, 41 U/L) and low potassium (K, 3.2 $\mathrm{mEq} / \mathrm{L}$ ) (Table 1). In the first day of admission, patient received $200 \mathrm{mg}$ of Hydroxychloroquine tablets twice daily (bd), $200 \mathrm{mg}$ of Lopinavir/ Ritonavir tablets twice daily (bd), and Oseltamivir tablets $75 \mathrm{mg}$ daily. On the second day, patient body temperature was reported $38.8 \mathrm{C}$ and the Wright test was found negative. Moreover, liver enzymes SGOT/AST and SGPT/ALT were elevated to 85 and $56 \mathrm{U} / \mathrm{L}$, respectively. Due patient's history and an episode of seizure during hospitalization, Levetiracetam $500 \mathrm{mg}$ intravenous (IV) daily and Levofloxacin tablets $750 \mathrm{mg}$ daily were added to his treatment. On $3^{\text {rd }}$ post-admission day, he had $380 \mathrm{C}$ fever. Sputum culture was performed which came back negative 48 hours later. Naproxen tablet 500 $\mathrm{mg}$ daily was added to his medication. On $7^{\text {th }}$ post-admission day, patient expired due to reduced oxygen pressure and asystole myocardial infarction.

\section{Discussion}

Underlying comorbidities are major risk factors for progression to critical illness and death in Covid-19 patients ${ }^{7-9}$. Amongst them, our patient had history of diabetes and epilepsy, which are associated with altered immune system response and potential poor prognosis in Covid-19 patients ${ }^{10-12,14-16}$. Weakened immune response might be related to mechanism in which these comorbidities modulate host-viral or hostimmune system interactions ${ }^{17,}{ }^{18}$. Specifically, it has been demonstrated that diabetes is a major risk factor for in-hospital mortality. Moreover, patient's urinary tract infection was assumed to be due to underlying comorbidities, especially diabetes and gout ${ }^{19,20}$. Development of acute kidney injury (AKI) in hospitalized Covid-19 patients is a negative prognostic factor and ranges between $3 \%$ to $29 \%$. Patient's proteinuria might be due to developed AKI during hospitalization which is highly associated with in hospital mortality ${ }^{21}$.

The presented case developed multiple organ failure induced by Covid-19. It is confirmed that Covid-19 can cause cytokine storm, in which high pro-inflammatory cytokines, as in the presented case, can lead to heart failure (CPK $340 \mathrm{U} / \mathrm{L}$ ), liver failure (elevated SGOT, SGPT, and Bilirubin), AKI, as well as respiratory failure (low PO2). Multiple organ failure is the most common cause of death in these patients ${ }^{22,23}$.

It is crucial to develop effective treatment regimens for Covid-19 patients with multiple comorbidities, as patients' past medical history is an essential contributor to possible organ injuries in these patients. Further observations will be required to comprehensively understand the full spectrum of Covid-19 clinical features in patients with multiple comorbidities.

\section{Conflicts of Interests}

The Authors declare that there are no competing interests.

\section{Author Contribution}

Amir Reza Safdarian: Significant author contribution following criteria as described by the International Committee of Medical Journal Editors (ICMJE).

Farima Kahe: Significant author contribution following criteria as described by the ICMJE.

Kaveh Momenzadeh: Significant author contribution following criteria as described by the ICMJE.

Pooya Farhangnia: Significant author contribution following criteria as described by the ICMJE. 
Nima Rezaei: Significant author contribution following criteria as described by the ICMJE.

\section{Acknowledgment}

We thank Mr. Saeed Samaeinasab for assistance with writing the introduction section.

\section{References}

1. Huang C, Wang Y, Li X, et al. Clinical features of patients infected with 2019 novel coronavirus in Wuhan, China. Lancet . Feb 15 2020;395(10223):497-506. doi:10.1016/S0140-6736(20)30183-5

2. Lu R, Zhao X, Li J, et al. Genomic characterisation and epidemiology of 2019 novel coronavirus: implications for virus origins and receptor binding. Lancet . Feb 22 2020;395(10224):565-574. doi:10.1016/S0140$6736(20) 30251-8$

3. Hanaei S, Rezaei N. COVID-19: Developing from an Outbreak to A Pandemic. Arch Med Res . May 13 2020;doi:10.1016/j.arcmed.2020.04.021

4. Chan-Yeung M, Xu RH. SARS: epidemiology. Respirology . Nov 2003;8 Suppl:S9-14. doi:10.1046/j.14401843.2003.00518.x

5. Morra ME, Van Thanh L, Kamel MG, et al. Clinical outcomes of current medical approaches for Middle East respiratory syndrome: A systematic review and meta-analysis. Rev Med Virol . May 2018;28(3):e1977. doi:10.1002/rmv.1977

6. Jabbari P, Jabbari F, Ebrahimi S, Rezaei N. COVID-19: A Chimera of Two Pandemics. Disaster Med Public Health Prep . Jun 25 2020:1-3. doi:10.1017/dmp.2020.223

7. Wang K, Chen W, Zhou Y-S, et al. SARS-CoV-2 invades host cells via a novel route: CD147-spike protein. bioRxiv . 2020;

8. Zheng Z, Peng F, Xu B, et al. Risk factors of critical \& mortal COVID-19 cases: A systematic literature review and meta-analysis. J Infect. Apr 23 2020;doi:10.1016/j.jinf.2020.04.021

9. Zhou F, Yu T, Du R, et al. Clinical course and risk factors for mortality of adult inpatients with COVID-19 in Wuhan, China: a retrospective cohort study. Lancet . Mar 28 2020;395(10229):1054-1062. doi:10.1016/S0140-6736(20)30566-3

10. Guo W, Li M, Dong Y, et al. Diabetes is a risk factor for the progression and prognosis of COVID-19. Diabetes Metab Res Rev. Mar 31 2020:e3319. doi:10.1002/dmrr.3319

11. Hussain A, Bhowmik B, do Vale Moreira NC. COVID-19 and diabetes: Knowledge in progress. Diabetes Res Clin Pract . Apr 2020;162:108142. doi:10.1016/j.diabres.2020.108142

12. Singh AK, Gupta R, Ghosh A, Misra A. Diabetes in COVID-19: Prevalence, pathophysiology, prognosis and practical considerations.Diabetes Metab Syndr. Apr 9 2020;14(4):303-310. doi:10.1016/j.dsx.2020.04.004

13. Huang YT, Lee YC, Hsiao CJ. Hospitalization for ambulatory-care-sensitive conditions in Taiwan following the SARS outbreak: a population-based interrupted time series study. J Formos Med Assoc . May 2009;108(5):386-94. doi:10.1016/S0929-6646(09)60082-6

14. Cabezudo-Garcia P, Ciano-Petersen NL, Mena-Vazquez N, Pons-Pons G, Castro-Sanchez MV, SerranoCastro PJ. Incidence and case fatality rate of COVID-19 in patients with active epilepsy. Neurology . Jun 17 2020;doi:10.1212/WNL.0000000000010033

15. Kuroda N. Epilepsy and COVID-19: Associations and important considerations. Epilepsy Behav . Jul 2020;108:107122. doi:10.1016/j.yebeh.2020.107122

16. Yasri S, Wiwanikit V. COVID-19 and Epilepsy. Ann Indian Acad Neurol . Apr 2020;23(Suppl 1):S43. doi:10.4103/aian.AIAN_254_20 
17. Yazdanpanah F, Hamblin MR, Rezaei N. The immune system and COVID-19: Friend or foe? Life Sci . Jun 2 2020;256:117900. doi:10.1016/j.lfs.2020.117900

18. Lotfi M, Rezaei N. SARS-CoV-2: A comprehensive review from pathogenicity of the virus to clinical consequences. J Med Virol . Jun 3 2020;doi:10.1002/jmv.26123

19. Singh JA, Cleveland JD. Serious Infections in People with Gout in the United States: A National Study of Incidence, Time-trends and Outcomes. Arthritis Care Res (Hoboken) . Apr 5 2020;doi:10.1002/acr.24201

20. Bono MJ, Reygaert WC. Urinary Tract Infection. StatPearls . 2020.

21. Cheng Y, Luo R, Wang K, et al. Kidney disease is associated with in-hospital death of patients with COVID-19. Kidney Int . May 2020;97(5):829-838. doi:10.1016/j.kint.2020.03.005

22. Rudrapal M, Khairnar SJ, Borse LB, Jadhav AG. Coronavirus Disease-2019 (COVID-19): An Updated Review. Drug Res (Stuttg) . Aug 3 2020;doi:10.1055/a-1217-2397

23. Sun YJ, Feng YJ, Chen J, Li B, Luo ZC, Wang PX. Clinical features of fatalities in patients with COVID-19. Disaster Med Public Health Prep . Jul 15 2020:1-10. doi:10.1017/dmp.2020.235

Table Legends

Table 1. Laboratory findings

\section{Hosted file}

Table 1.docx available at https://authorea.com/users/360262/articles/481936-death-due-tocovid-19-in-a-patient-with-diabetes-epilepsy-and-gout-comorbidities 